\title{
Aberrant Vimentin Methylation Is Characteristic of Breast Cancer
}

\author{
F. I. Dwedar'1, G. I. Khalil'², S. A. Nayer³, A. Farouk ${ }^{4}$ \\ ${ }^{1}$ Department of Medical Biochemistry, Faculty of Medicine, Alexandria University, Alexandria, Egypt \\ ${ }^{2}$ Department of Chemical Pathology, Medical Research Institute, Alexandria University, Alexandria, Egypt \\ ${ }^{3}$ Department of Cancer Management and Research, Medical Research Institute, Alexandria University, Alexandria, Egypt \\ ${ }^{4}$ Department of Clinical \& Experimental Surgery, Medical Research Institute, Alexandria University, Alexandria, Egypt \\ Email:snayer45@gmail.com
}

How to cite this paper: Dwedar, F.I., Khalil, G.I., Nayer, S.A. and Farouk, A. (2016) Aberrant Vimentin Methylation Is Characteristic of Breast Cancer. Advances in Breast Cancer Research, 5, 150-162.

http://dx.doi.org/10.4236/abcr.2016.54018

Received: September 2, 2016

Accepted: October 16, 2016

Published: October 19, 2016

Copyright $\odot 2016$ by authors and Scientific Research Publishing Inc. This work is licensed under the Creative Commons Attribution International License (CC BY 4.0).

http://creativecommons.org/licenses/by/4.0/

(c) () Open Access

\begin{abstract}
Background: Epigenetic mechanisms including DNA methylation are key regulators of gene activity and may play key roles in carcinogenesis through cumulative activation and inactivation of oncogenes, tumor suppressor genes, and other genes. Increased vimentin gene expression has been reported in various tumor cell lines and tissues including breast cancer. In addition, methylation of the vimentin gene was described as a marker in several malignant tumors. Objective: The aim of this study is to determine the existence of a potential relationship between the methylation state of the vimentin gene and its prognostic value in breast cancer patients and its correlation with vimentin protein expression in the serum. Patients and Methods: The methylation status of the vimentin gene was examined in primary infiltrating ductaltumors and the surrounding normal tissues derived from 50 breast cancer patients enrolled for either modified radical mastectomy or conservative breast surgery using quantitative methylation-specific polymerase chain reaction (qMSP), serum vimentin levels were determined using ELISA, and the correlation between the methylation status and the clinicopathological findings was evaluated. Results: Out of 50 breast cancer patients, 18 (36\%) exhibited positive methylation of vimentin gene while 32 (64\%) exhibited negative vimentin genemethylation in their tumors. Subsequently clinicopathological data were correlated with the vimentin genemethylation score. A significant association was found between negative vimentin methylation, and both serum vimentin protein level $(\mathrm{p}<0.001)$ and the triple negative breast cancer subtype (TNBCs) $(\mathrm{p}=0.004)$. Using receiver-operating characteristic $(\mathrm{ROC})$ curve analysis, a cut off value of $<0.49$ was set for the negative vimentin methylation score to distinguish between early and late stage breast cancer, and the ROC curve showed an area under the curve (AUC) of $0.684(\mathrm{p}=0.029)$. Conclusion: Our study showed that the vimentin gene is frequently hypomethylated in breast cancer tissues, and that
\end{abstract}


negative methylation status is always associated with high serum vimentin protein expression levels. Also we reported a significant association between negative vimentin methylation and TNBC subtype which is known to have an aggressive clinical course. Taken together, these results might have important implications for the design of novel therapeutic interventions for breast cancer patients. However, further studies with larger sample size are needed to validate these observations.

\section{Keywords}

DNA Methylation, Breast Cancer, Vimentin, Epigenetic, TNBCs

\section{Introduction}

Worldwide, breast cancer is considered as one of the most common cancers with greater than 1,300,000 cases and 450,000 deaths each year [1]. In Egypt, the pattern of malignancy occurrence in Lower, Middle, and Upper Egypt was dominated by the high frequency of female breast cancer $(33.8 \%, 26.8 \%$ and $38.7 \%$ respectively) [2]. The progression of breast cancer involves various stages until the invasive carcinoma occurrence and finally into metastatic disease. Given the variability in clinical progression in breast cancer, the identification of markers that could predict the tumor behavior is particularly important [3]. Among diagnostic techniques, DNA methylation based biomarker could help as an important tool for the diagnosis of many cancers, including breast cancer [4]. DNA methylation, which most commonly occurs at CpG dinucleotides regions, has been associated with many clinicopathological features in breast cancer patients, such as tumor stage, histological grade, and TP53 status [5] [6]. Furthermore, DNA hypomethylation and hypermethylation can impact breast cancer progression and prognosis, contributing to the overexpression of oncogenes and down regulation of tumor suppressor genes, respectively [7].

Vimentin is an intermediate filament protein of mesenchymal cells, which is commonly used to identify cells undergoing Epithelial-Mesenchymal Transition (EMT) in cancer. Moreover, it was found that its expression is associated with increased risk of metastasis and poor prognosis in breast cancer patients [8]. In spite that upregulation of Vimentin expression during EMT which has been well characterized in breast cancer, only few to our knowledge have reported epigenetic changes in Vimentin derived from breast tumors [9] [10]. Numerous studies have explored epigenetic changes in Vimentin in general, with data showing differential Vimentin DNA methylation in other solid tumors such as colorectal, gastric, cervical, bladder, and pancreatic cancer [11]-[14].

Therefore, we intended to quantify vimentin methylation in fifty infiltrating ductal breast carcinoma specimens and matched normal tissue and to test for associations of methylation of the vimentin gene and its protein expression in the serum, in addition to find out the correlation between vimentin methylation and prognostic markers such as tumor size, tumor stage, lymph node metastasis, breast cancer subtype and CA15-3. 


\section{Materials and Methods}

\subsection{Patients and Specimens}

Primary infiltrating ductal carcinoma and paired normal tissue specimens as well as serum samples were obtained from 50 breast cancer patients who underwent surgery at the Department of Surgery at the Medical Research Institute Hospital, Alexandria University, between June 2013 and December 2015. All patients did not receive neoadjuvant chemotherapy, radiotherapy or hormonal therapy. Before surgery, all patients in this study were subjected to full history taking, thorough clinical examination, fine needle aspiration cytology (FNAC) or excision biopsy from the breast mass for pathological examination, laboratory investigations including CBC, fasting blood sugar, liver functions, kidney functions, tumor markers, and radiological examination including mammography and ultrasound of both breasts, pelvi-abdominal ultrasound, chest Xray as well as bone scan. Postoperative pathology examination as well as hormonal receptors (ER \& PR), and epidermal growth factor receptor 2(HER-2) were done. Clinical staging was performed according to tumor-node-metastasis classification system (TNM) [15]. Thirty patients were of stage II and twenty were of stage III. In addition, a group of 20 age and sex matched healthy volunteers served as a control group for evaluation of the serum vimentin protein level. Written informed consent was obtained from all patients. The study approval was obtained from the ethics committee of our institute.

Surgical procedures: Patients with breast cancer were subjected to surgical intervention including modified radical mastectomy (MRM) in 37 patients, and conservative breast surgery (CBS) in the remaining 13 patients.

\subsubsection{Evaluation of ER, PR, and HER2 Status}

The ER, PR, and HER2 status were examined as previously reported [16]. ER and PR were considered to be positive if $>1 \%$ of the nuclei of cancer cells were stained by immunohistochemistry (IHC). Tumors were considered to be HER2 positive only if they were scored $3+$ by IHC or $2+$ by IHC in combination with HER2 amplification (ratio > 2.0) by fluorescence in situ hybridization.

\subsubsection{Sample Collection and DNA Preparation}

Genomic DNA was isolated from snap-frozen tissue biopsies using the QIAamp DNA Mini Kit (QIAGEN, Hilden, Germany) as described by the manufacturer [17].

\subsubsection{Sodium Bisulfite Treatment.}

One $\mu \mathrm{g}$ of the genomic DNA extracted from the breast cancer specimens was subjected to bisulfite treatment using an Epitect Bisulfite Kit (Qiagen, Hilden, Germany) as described elsewhere [18]. The chemical modification of cytosine to uracil by bisulfite treatment provides a sensitive method for the study of DNA methylation. Incubation of the target DNA with sodium bisulfite results in conversion of unmethylated cytosine residues into uracil, leaving the methylated cytosines unchanged. Therefore, bisulfite treatment gives rise to different DNA sequences for methylated and unmethylated DNA. This altered DNA can then be amplified, providing detailed information within 
the amplified region of the methylation status of all CpG sites. The EpiTect Bisulfite procedure comprises a few simple steps: bisulfite-mediated conversion of unmethylatedcytosines; binding of the converted single-stranded DNA to the membrane of an EpiTect spin column; washing; desulfonation of membrane-bound DNA; washing of the membrane-bound DNA to remove desulfonation agent; and elution of the pure, converted DNA from the spincolumn.

\subsubsection{Quantitative Methylation-Specific Polymerase Chain Reaction (qMSP)}

The bisulfite-treated DNA was amplified with a qMSP that was performed using DyNAmo Flash SYBR Green qPCR Kit provided by Thermo Fisher Scientific, Inc. in a thermal cycler (Applied BiosystemsStepOne ${ }^{\mathrm{rm}}$ Real-Time PCR System). Thermocycling was carried out in afinal volume of $25 \mu$ containing $1.0 \mu \mathrm{l}$ of the DNA sample, $100 \mathrm{nM}$ each of the Vimentin or $\beta$-actin primers (forward and reverse), and $12.5 \mu \mathrm{l}$ of SYBR Master mix which contains hot-start version of a modified Thermusbrockianus $\mathrm{Tbr}$ DNA polymerase, SYBR Green I, optimized PCR buffer, $5 \mathrm{mM} \mathrm{MgCl}$, dNTP mix including dUTP.

The qPCR primer sequences for Vimentin have been described [19] and were: Vimentin MS (sense), 5'TCGTTTCGAGGTTTTCGCGTTAGAGAC-3', and Vimentin MAS (antisense), 5'CGACTAAAACTCGACCGACTCGCGA-3'. The PCR amplification consisted of 40 cycles $\left(95^{\circ} \mathrm{C}\right.$ for $5 \mathrm{~s}$ and $55^{\circ} \mathrm{C}$ for $30 \mathrm{~s}$ ) after an initial denaturation step $\left(95^{\circ} \mathrm{C}\right.$ for $\left.10 \mathrm{~s}\right)$. To ensure the specificity, a negative control (no template control) and a positive control (using EpiTect Control DNA) were included in each run. To normalize input DNA amounts, a companion real-time PCR assay was designed against bisulfite converted actin gene sequences that lack $\mathrm{CpG}$ dinucleotides and so are not modified by methylation. The assay for Actin was designed to generate an amplification product of the same size as the assay for methylated vimentin. The actin forward primer was GGATAGGATAGTTTTATTTTTAG, and the actin reverse primer was ATACAAAACTATACTCAACCAA [20].

Vimentin methylation scores: The relative amounts of Vimentin methylated DNA in the breast cancer tissue that were normalized to the internal control $\beta$-actin $(\Delta \mathrm{CT})$ were calculated. The vimentin methylation score in each tissue was defined as follows: relative amount of vimentin in tumor/mean relative amount of vimentin in all corresponding normal tissues. Vimentin methylation was considered positive when the methylation score was more than 1.0 and considered negative when the methylation score was less than 1.0 [21].

Vimentin protein serum levels were determined by enzyme linked immunosorbent assay (ELISA) [22]. The kit was supplied by Uscn. Life Science Inc.

\subsubsection{Statistical Analysis of the Data}

Data were fed to the computer and analyzed using IBM SPSS software package version 20.0. Comparisons between groups for categorical variables were assessed using Chisquare test. Student t-test was used to compare two groups for normally distributed quantitative variables while ANOVA was used for comparing the three studied groups. 
Receiver operating characteristic curve (ROC) was used to determine the diagnostic performance of the markers. Area more than $50 \%$ gives acceptable performance and area about $100 \%$ is the best performance for the test. Significance of the obtained results was judged at the $5 \%$ level.

\section{Results}

We first examined the methylation status of vimentin gene in breast cancer tissue samples and matched normal pairs using qMSP. Out of 50 breast cancer patients, 18 (36\%) exhibited positive methylation of vimentin and $32(64 \%)$ exhibited negative vimentin methylation in their tumor specimens, among these negative cases, 11 cases were of the triple negative breast cancer (TNBC) subtype. Our results suggest that the aberrant methylation of the vimentin gene was frequent in breast cancer patients, moreover a significant association was shown between the TNBC subtype cases and negative vimentin methylation $(\mathrm{p}=0.004)$ (Table 1$)$.

Subsequently we used ELISA technique to measure the vimentin protein concentration in serum samples. The mean serum vimentin concentration in cancer patients (1134.62 \pm 613.68) was significantly higher than that in healthy donors $(454.60 \pm$ 208.87, p < 0.001) (Table 2). While, the mean serum vimentin level among stage III cases $(1246.50 \pm 718.49)$ was higher than that of stage II cases $(1060.03 \pm 532.66)$. However, it did not reach the level of statistical significance $(\mathrm{p}=0.082)$ (Table 3$)$.

Then, clinicopathological data were tested for association with the vimentin methylation scores (Table 1). No association was found between the aberrant vimentin methylation in breast cancer and patient' age, tumor size, lymph node metastasis, vascular invasion, Her 2 neu, ER and serum CA15-3 level. However, a significant association was observed between negative vimentin methylation in breast cancer tissues and serum vimentin level, the mean serum vimentin protein level was significantly higher in patients with negatively methylated gene than those with positive methylation ( $\mathrm{p}<$ 0.001). Also, a significant association was observed between the negative vimentin methylation and the TNBC subtype $(\mathrm{p}=0.004)$.

Using receiver-operating characteristic (ROC) curve analysis, a cut off value of $<0.49$ was set for the vimentin methylation score to distinguish between stage II (early stage) and stage III (late stage) breast cancer cases. The ROC curve showed an AUC of 0.684 ( $p=0.029$ ), a sensitivity of $45 \%$ and a specificity of $86.67 \%$ for diagnosis of late stage breast cancer, in comparison with serum CA15-3 levels for diagnosis of late stage breast cancer patients It revealed that at the cut off value of $46 \mathrm{ng} / \mathrm{ml}$ the AUC was 0.945 (p < 0.001 ), a sensitivity of $90 \%$ and a specificity of $96.67 \%$ (Figure 1 ).

\section{Discussion}

Several strong risk factors, ranging from genetic to environmental, have been identified for breast cancer [23]. In addition, convenient and accurate early detection techniques have been developed and are in routine use [24]. While, these strategies were supposed to reduce the fatality rates of breast cancer, unfortunately half a million women still die 
Table 1. Association between vimentin methylation and the clinicopathological characteristics of studied patients.

\begin{tabular}{|c|c|c|c|}
\hline \multirow{2}{*}{ Characteristics } & \multicolumn{2}{|c|}{ Vimentin methylation } & \multirow{2}{*}{$\mathrm{p}$} \\
\hline & Negative $(n=32)$ & Positive $(n=18)$ & \\
\hline \multicolumn{4}{|l|}{ Age (years) } \\
\hline$\leq 50$ & $16(50.0 \%)$ & $9(50.0 \%)$ & \multirow{2}{*}{1.000} \\
\hline$>50$ & $16(50.0 \%)$ & $9(50.0 \%)$ & \\
\hline \multicolumn{4}{|l|}{ Tumor size $(\mathrm{cm})$} \\
\hline$<3$ & $12(37.5 \%)$ & $5(27.8 \%)$ & \multirow{2}{*}{0.486} \\
\hline$\geq 3$ & $20(62.5)$ & $13(72.2)$ & \\
\hline \multicolumn{4}{|l|}{ LN metastasis } \\
\hline Negative & $17(53.1 \%)$ & $10(55.6 \%)$ & \\
\hline Positive & $15(46.9 \%)$ & $8(44.4 \%)$ & \\
\hline \multicolumn{4}{|l|}{ Vas invasion } \\
\hline Positive & $25(78.1 \%)$ & $14(77.8 \%)$ & \multirow{2}{*}{1.000} \\
\hline Negative & $7(21.9 \%)$ & $4(22.2 \%)$ & \\
\hline \multicolumn{4}{|l|}{ Her 2 neu } \\
\hline Negative & $20(62.5 \%)$ & $11(61.1 \%)$ & \multirow{2}{*}{0.923} \\
\hline Positive & $12(37.5 \%)$ & $7(38.9 \%)$ & \\
\hline \multicolumn{4}{|l|}{ P R } \\
\hline Negative & $11(34.4 \%)$ & $1(5.6 \%)$ & \multirow{2}{*}{$0.036^{*}$} \\
\hline Positive & $21(65.6 \%)$ & $17(94.4 \%)$ & \\
\hline \multicolumn{4}{|l|}{ E R } \\
\hline Negative & $12(37.5 \%)$ & $2(11.1 \%)$ & \multirow{2}{*}{0.046} \\
\hline Positive & $20(62.5 \%)$ & $16(88.9 \%)$ & \\
\hline \multicolumn{4}{|l|}{ Subtypes } \\
\hline TNBC & $11(34.4 \%)$ & $0(0.0 \%)$ & \multirow{2}{*}{$0.004^{*}$} \\
\hline Non TNBC & $21(65.6 \%)$ & $18(100.0 \%)$ & \\
\hline \multicolumn{4}{|l|}{ TNM stage } \\
\hline Stage II & $17(53.1 \%)$ & $13(72.2 \%)$ & \multirow{2}{*}{0.186} \\
\hline Stage III & $15(46.9 \%)$ & $5(27.8 \%)$ & \\
\hline Serum vimentin $(\mathrm{ng} / \mathrm{ml})$ & $1385.34 \pm 537.25$ & $688.89 \pm 480.09$ & $<0.001^{*}$ \\
\hline Serum Ca 15-3 & $53.38 \pm 16.17$ & $47.44 \pm 13.03$ & 0.190 \\
\hline
\end{tabular}

Qualitative data were described using number and percent and was compared using Chi square test, while normally quantitative data was expressed in mean $\pm \mathrm{SD}$ and was compared using student $\mathrm{t}$-test. ${ }^{*}$ : Statistically significant at $\mathrm{p} \leq$ 0.05 .

Table 2. Comparison between the two studied groups according to serum vimentin levels (ng/ml).

\begin{tabular}{cccc}
\hline & Patients $(\mathrm{n}=50)$ & (Control) $(\mathrm{n}=20)$ & $\mathrm{p}$ \\
Serum vimentin & $1134.62 \pm 613.68$ & $454.60 \pm 208.87$ & $<0.001^{*}$ \\
\hline
\end{tabular}

Normally quantitative data was expressed as Mean \pm SD and compared using Student t-test. *: Statistically significant at $\mathrm{p} \leq 0.05$. 
Table 3. Comparison between three studied groups according to serum vimentin levels (ng/ml).

\begin{tabular}{crccc}
\hline & Stage II $(\mathrm{n}=\mathbf{3 0})$ & Stage III $(\mathrm{n}=20)$ & Control $(\mathrm{n}=20)$ & $\mathrm{p}$ \\
\hline Serum vimentin & $1060.03 \pm 532.66$ & $1246.50 \pm 718.49$ & $454.60 \pm 208.87$ & $<0.001^{*}$ \\
Sig. bet. Grps & $\mathrm{p}_{1}=0.314, \mathrm{p}_{2}<0.001^{*}, \mathrm{p}_{3}<0.001^{*}$ & \\
\hline
\end{tabular}

Normally quantitative data was expressed as Mean \pm SD and compared using F test (ANOVA). $\mathrm{p}_{1}$ : $\mathrm{p}$ value for Post Hoc test (LSD) for comparing between stage II and stage III. $\mathrm{p}_{2}$ : $\mathrm{p}$ value for Post Hoc test (LSD) for comparing between stage II and control. $\mathrm{p}_{3}$ : $\mathrm{p}$ value for Post Hoc test (LSD) for comparing between stage III and control. *: Statistically significant at $\mathrm{p} \leq 0.05$.

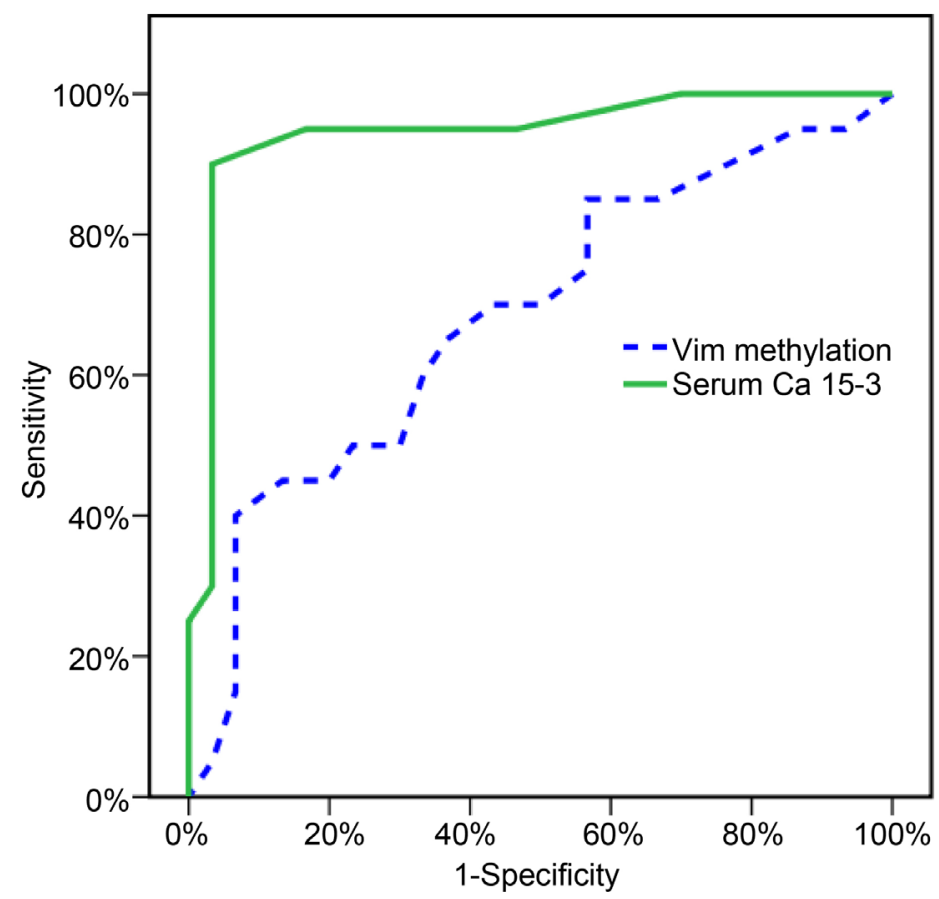

Figure 1. ROC curve for comparison between vimentin methylation score and Serum Ca 15 - 3 for diagnosis of late stage breast cancer patients.

of the disease each year, among those, more than $90 \%$ were due to cancer metastasis. Therefore, extensive research and clinical efforts were required to clarify and understand the molecular mechanisms of metastatic spread of tumor cells in order to target these mechanisms, by pharmaceutical or genetic-based approaches resulting in slowing down or stopping metastasis and consequently improving the survival of cancer patients [25].

Vimentin is an intermediate filament protein expressed in tissues of normal mesenchymal origin. It is known also that vimentin is expressed aberrantly in epithelial cancers such as prostate, lung, central nervous system and breast [26]. Its expression is associated with increased risk of metastasis and poor prognosis in breast cancer patients [7]. In addition, vimentin gene was shown to be a target of epigenetic modifications. [18] Increased DNA methylation is an epigenetic alteration that is common in human cancers. Alterations in the DNA methylation profile have been associated with changes of gene expression and prognosis in breast cancer [27]. Given the poor prognosis of 
breast cancers having elevated Vimentin expression [28] [29], our central hypothesis was that if aberrant Vimentin methylation was correlated with increased gene expression thenit could be a target for cancer therapy.

In an effort to identify a methylation-based biomarker for breast cancer, we evaluated the levels of vimentin gene methylation in human breast cancer tissue samples as well as vimentin protein levels in their sera. Our study showed that among 50 breast cancer cases enrolled in the study 32 of them (64\%) revealed negative vimentin gene methylation while 18 cases (36\%) exhibited positive vimentin methylation and that this vimentin negative methylation was significantly associated with elevated vimentin protein level in the serum of these patients. Mean serum vimentin level in cancer patients was significantly higher than that in healthy donors $(\mathrm{p}<0.001)$. Elevated serum vimentin level in cancer cases could be due to secretion of vimentin into the circulation early during tumorigenesis and this may be related to the promotion of the innate immunity. Vimentin has been reported to be secreted into the extracellular space by activated macrophages [30]. Our results suggested that the increased serum vimentin level in breast cancer resulted from negative methylation of vimentin gene and consequently increased expression of the vimentin gene intracellularly leading to secretion of high levels of soluble vimentin in the serum, nevertheless, the mechanism that triggers the secretory pathways whether from necrosis/apoptosis or active release from the cancer cells remains to be elucidated.

Moreover, a statistically significant performance of the vimentin methylation score for diagnosis of late stage group was observed using ROC curve at the cut off value of $<$ 0.49 (AUC $=0.684, \mathrm{p}=0.029$ ). These results suggested that negative methylation of vimentin gene would relate to the progression of carcinogenesis. DNA methylation has a substantial impact on gene expression, affecting the prognosis of breast cancer patients ${ }^{[26]}$. The vimentin gene which was normally silenced by methylation, may exhibit demethylation and become actively transcribed and overexpressed in the cells [18]. Vimentin is the major cytoskeletal component of mesenchymal cells. So, it is often used as a marker of (EMT), a process often associated with the malignant progression and cancer aggressiveness in which the epithelial cells acquire a mesenchymal phenotype that renders the cells alter their shape and exhibit increased motility with enhanced metastatic and invasive potential [31]. A hallmark of EMT is the loss of epithelial characteristics such as a decrease in the expression of the cell adhesion molecular E-cadherin and increased expression of vimentin IFs in epithelial cells [32].

Gjerdum et al. 2010 [33] reported that vimentin plays a crucial role in the EMT process in breast cancers, and its knockdown causes a decrease in genes linked to breast cancer metastasis, such as the receptor tyrosine kinase, Axl. Thus, vimentin is an important upstream effect or of EMT signaling that can encounter aggressiveness of breast cancer [33] [34]. In line with the same context, vimentin expression was more associated with the invasive phenotype of gastric carcinoma [35], esophageal squamous cell carcinoma [36], and in colorectal cancer cells [37] [38]. Moreover, vimentin showed overexpression in pancreatic cancers and increased the invasive potential of pancreatic 
cancer cells [39] [40]. In addition, vimentin expression was shown to be elevated in aggressive breast cancer [41] primary malignant melanomas [42], CNS tumors [43]. Its overexpression in all these types of cancer was very well correlated with increased migration and invasion of cancer cells. In contrast, it was observed that over-expression of vimentin in HCC cells decreased their proliferative and invasive capabilities in vitro [44] [45].

Meanwhile, using MALDI-TOF mass spectrometry to quantify vimentin methylation in breast tumors and breast cancer cell lines, Ulirsch et al. 2013 [9], found that vimentin was differentially methylated in both luminal A and luminal B cell lines and in luminal and HER2-enriched molecular tumor subtypes, but low to nil methylation was found in $91 \%$ of the basal-like tumors. Overall, increased methylation was negatively correlated with vimentin mRNA levels quantified via qRT-PCR in cell lines and by oligomicroarray in breast tumors. This is in accordance with our current results where $100 \%$ of the TNBC cases exerted negative methylation while the vimentin gene was positively methylated among the non-TNBC cases.

Also, in agreement with our study, Zhou et al. 2014 [14], found that of 64 pancreatic cancer tissues, only 21 of them displayed positive vimentin methylation while 45 of them exhibited negative methylation, moreover, its survival analysis revealed that vimentin methylation status was an independent prognostic factor as well as prognostic marker in T-staging and adjuvant chemotherapy, and that low methylation is always associated with high vimentin expression levels.

In contrast, Shirahata et al. 2009 [21], showed that aberrant methylation of the vimentin gene is frequently found to be methylated in advanced colorectal carcinomas and is closely related with colorectal carcinomas. Chen et al. 2005 [46], found that vimentin gene is transcriptionally inactive in normal colon epithelial cells with very low level of methylation on $\mathrm{CpG}$ region near the first exon. However, this region is found to be highly methylated in primary tumor of colon cancer. Costa et al. 2010 [13], suggested vimentin gene as a biomarker that allows for early detection of bladder cancer using urine samples. The methylation levels in vimentin gene were significantly higher in bladder cancer tissues compared to normal bladder mucosa. Kitamura et al. 2009 [12], demonstrated that well-differentiated adenocarcinoma was significantly methylated in gastric carcinomas when compared to poorly differentiated. These findings merit an explanation as it is well known that transcription of several tumor suppressor genes is found to be inactivated by promoter hypermethylation in many cancer cells so, it was expected from the results of these studies that vimentin may act as a tumor suppressor gene, which is not true, since many studies involving vimentin have suggested that vimentin appears to have an oncogenic characteristics rather than to suppress a tumorigenic phenotypes [4].

\section{Conclusion}

The results of the present study clearly indicate that negative methylation of the EMT marker vimentin is frequent among breast cancer patients with early and late stage, and 
that negative methylation status is always associated with high serum vimentin protein expression levels. Also a significant association between negative vimentin methylation and TNBC subtype which is known to have aggressive clinical course was reported. Taken together, these results might have important implications for the design of novel therapeutic interventions for breast cancer patients. If negative vimentin methylation was correlated with increased gene expression, then increased methylation would be a target for cancer therapy. However, further studies with larger sample size are needed to validate these observations.

\section{References}

[1] Cancer Genome Atlas Network (2012) Comprehensive Molecular Portraits of Human Breast Tumours. Nature, 490, 61-70. http://dx.doi.org/10.1038/nature11412

[2] Ibrahim, A.S., Khaled, H.M., Mikhail, N.N.H., Baraka, H. and Kamel, H. (2014) Cancer Incidence in Egypt: Results of the National Population-Based Cancer Registry Program. Journal of Cancer Epidemiology, 2014, Article ID: 437971. http://dx.doi.org/10.1155/2014/437971

[3] Karina, B., Hirata, B., Oda, J.M.M., Guembarovski, R.L., Ariza, C.B., de Oliveira, C.E.C. and Watanabe, M.A.E. (2014) Molecular Markers for Breast Cancer: Prediction on Tumor Behavior. Disease Markers, 2014, Article ID: 513158. http://dx.doi.org/10.1155/2014/513158

[4] Jung, S., Yi, L.S., Kim, J.S., Jeong, D.J., Oh, T., Kim, C.-H., Kim, C.-J., Shin, J., An, S. and Lee, M.-S. (2011) The Role of Vimentin as a Methylation Biomarker for Early Diagnosis of Cervical Cancer. Molecules and Cells, 31, 405-411.

[5] Fleischer, T., Frigessi, A., Johnson, K.C., et al. (2014) Genome-Wide DNA Methylation Profiles in Progression to in Situ and Invasive Carcinoma of the Breast with Impact on Gene Transcription and Prognosis. Genome Biology, 15, 435.

[6] Fleischer, T., Edvardsen, H., Solvang, H.K., et al. (2014) Integrated Analysis of High-Resolution DNA Methylation Profiles, Gene Expression, Germline Genotypes and Clinical End Points in Breast Cancer Patients. International Journal of Cancer, 134, 2615-2625. http://dx.doi.org/10.1002/ijc.28606

[7] Jovanovic, J., Ronneberg, J.A., Tost, J., et al. (2010) The Epigenetics of Breast Cancer. Molecular Oncology, 4, 242-254. http://dx.doi.org/10.1016/j.molonc.2010.04.002

[8] Kallerg, G., Papadak, M.A., Politaki, E., Mavroudis, D., Georgoulias, V. and Agelaki, S. (2011) Epithelial to Mesenchymal Transition Markers Expressed in Circulating Tumour Cells of Early and Metastatic Breast Cancer Patients. Breast Cancer Research, 13, 59. http://dx.doi.org/10.1186/bcr2896

[9] Ulirsch, J., Fan, C., Knafl, G., Wu, M.J., Coleman, B., Perou, C.M. and Swift-Scanlan, T. (2013) Vimentin DNA Methylation Predicts Survival in Breast Cancer. Breast Cancer Research and Treatment, 137, 383-396. http://dx.doi.org/10.1007/s10549-012-2353-5

[10] Fackler, M.J., Umbricht, C.B., Williams, D., Argani, P., Cruz, L.A., Merino, V.F., Teo, W.W., Zhang, Z., Huang, P., Visvananthan, K., Marks, J., Ethier, S., Gray, J.W., Wolff, A.C., Cope, L.M. and Sukumar, S. (2011) Genome-Wide Methylation Analysis Identifies Genes Specific to Breast Cancer Hormone Receptor Status and Risk of Recurrence. Cancer Research, 71, 6195-6207. http://dx.doi.org/10.1158/0008-5472.CAN-11-1630

[11] Itzkowitz, S.H., Jandorf, L., Brand, R., Rabeneck, L., Schroy, P.C., Sontag, S., Johnson, D., Skoletsky, J., Durkee, K., Markowitz, S. and Shuber, A. (2007) Improved Fecal DNA Test for Colorectal Cancer Screening. Clinical Gastroenterology and Hepatology, 5, 111-117. 
http://dx.doi.org/10.1016/j.cgh.2006.10.006

[12] Kitamura, Y.H., Shirahata, A., Sakata, M., Goto, T., Mizukami, H., Saito, M., Ishibashi, K., Kigawa, G., Nemoto, H., Sanada, Y. and Hibi, K. (2009) Frequent Methylation of Vimentin in Well-Differentiated Gastric Carcinoma. Anticancer Research, 29, 2227-2229.

[13] Costa, V.L., Henrique, R., Danielsen, S.A., Duarte-Pereira, S., Eknaes, M., Skotheim, R.I., Rodrigues, A., Magalhaes, J.S., Oliveira, J., Lothe, R.A., Teixeira, M.R., Jeronimo, C. and Lind, G.E. (2010) Three Epigenetic Biomarkers, GDF15, TMEFF2, and, VIM, Accurately Predict Bladder Cancer from DNA-Based Analyses of Urine Samples. Clinical Cancer Research, 16, 5842-5851. http://dx.doi.org/10.1158/1078-0432.CCR-10-1312

[14] Zhou, Y.F., Xu, W., Wang, X., Sun, J.S., Xiang, J.J., Li, Z.S. and Zhang, X.F. (2014) Negative Methylation Status of Vimentin Predicts Improved Prognosis in Pancreatic Carcinoma. World Journal of Gastroenterology, 20, 13172-13177. http://dx.doi.org/10.3748/wjg.v20.i36.13172

[15] Edge, S.B. (2010) Breast. In: Edge, S.B., Byrd, D.R. and Compton, C.C., Eds., AJCC Cancer Staging Manual, 7th Edition, Springer, New York, 347-376.

[16] Tokunaga, E., Kimura, Y., Oki, E., Ueda, N., Futatsugi, M., Mashino, K., Yamamoto, M., Ikebe, M., Kakeji, Y., Baba, H. and Maehara, Y. (2006) Akt Is Frequently Activated in HER2/Neu-Positive Breast Cancers and Associated with Poor Prognosis among HormoneTreated Patients. International Journal of Cancer, 118, 284-289. http://dx.doi.org/10.1002/ijc.21358

[17] Wong, I.H., Lo, Y.M., Zhang, J., Liew, C.T., Ng, M.H., Wong, N., et al. (1999) Detection of Aberrant P16 Methylation in the Plasma and Serum of Liver Cancer Patients. Cancer Research, 59, 71-73.

[18] Tiwari, S.K., Manoj, G., Prasanth, K., Sivaram, G., Sharma, V.K., Habeeb, M.A., et al. (2009) Simplified and Versatile Method for Bisulfite-Based DNA Methylation Analysis of Small Amounts of DNA. Journal of Clinical Laboratory Analysis, 23, 172-174. http://dx.doi.org/10.1002/jcla.20314

[19] Kitamura, Y., Shirahata, A., Sakuraba, K., Goto, T., Mizukami, H., Saito, M., et al. (2011) Aberrant Methylation of the Vimentin Gene in Hepatocellular Carcinoma. Anticancer Research, 31, 1289-1291.

[20] Moinova, H., Leidner, R.S., Ravi, L., Lutterbaugh, J., Barnholtz-Sloan, J.S., Chen, Y., Chak, A., Markowitz, S.D. and Willis, J.E. (2012) Aberrant Vimentin Methylation Is Characteristic of Upper Gastrointestinal Pathologies. Cancer Epidemiology Biomarkers \& Prevention, 21, 594-600. http://dx.doi.org/10.1158/1055-9965.EPI-11-1060

[21] Shirahata, A., Sakata, M., Sakuraba, K., Goto, T., Mizukami, H., Saito, M., Ishibashi, K., Kigawa, G., Nemoto, H. and Sanada, Y. (2009) Vimentin Methylation as a Marker for Advanced Colorectal Carcinoma. Anticancer Research, 29, 279-281.

[22] Wong, K.F. and Luk, J.M. (2012) Discovery of Lamin b1 and Vimentin as Circulating Biomarkers for Early Hepatocellular Carcinoma. Methods in Molecular Biology, 909, 295-310.

[23] Rybarova, S., Vecanova, J., Hodorova, I., et al. (2011) Association between Polymorphisms of XRCC1, p53 and MDR1 Genes, the Expression of Their Protein Products and Prognostic Significance in Human Breast Cancer. Medical Science Monitor, 17, 354-363. http://dx.doi.org/10.12659/MSM.882121

[24] Tvrdik, D., Skalova, H., Dundr, P., et al. (2012) Apoptosis-Associated Genes and Their Role in Predicting Responses to Neoadjuvant Breast Cancer Treatment. Medical Science Monitor, 18, 60-67. http://dx.doi.org/10.12659/MSM.882205

[25] Liu, Y., Zhao, J., Zhang, P., Zhang, Y., Sun, S., Yu, S. and Xi, Q. (2012) MicroRNA-10b 
Targets E-Cadherin and Modulates Breast Cancer Metastasis. Medical Science Monitor, 18, 299-308. http://dx.doi.org/10.12659/MSM.883262

[26] Satelli, A. and Li, S. (2011) Vimentin as a Potential Molecular Target in Cancer Therapy or Vimentin, an Overview and Its Potential as a Molecular Target for Cancer Therapy. Cellular and Molecular Life Sciences, 68, 3033-3046. http://dx.doi.org/10.1007/s00018-011-0735-1

[27] Gyorffy, B., Bottai, G., Fleischer, T., Munkacsy, G., Budczies, J., Paladini, L., et al. (2016) Aberrant DNA Methylation Impacts Gene Expression and Prognosis in Breast Cancer Subtypes. International Journal of Cancer, 138, 87-97. http://dx.doi.org/10.1002/ijc.29684

[28] Yamashita, N., Tokunaga, E., Kitao, H., Hisamatsu, Y., Taketani, K., Akiyoshi, S., et al. (2013) Vimentin as a Poor Prognostic Factor for Triple-Negative Breast Cancer. Journal of Cancer Research and Clinical Oncology, 139, 739-746.

http://dx.doi.org/10.1007/s00432-013-1376-6

[29] Karihtala, P., Auvinen, P., Kauppila, S., Haapasaari, K.M., Jukkola-Vuorinen, A. and Soini, Y. (2013) Vimentin, Zeb1 and Sip1 Are Up-Regulated in Triple-Negative and Basal-Like Breast Cancers: Association with an Aggressive Tumour Phenotype. Breast Cancer Research and Treatment, 138, 81-90. http://dx.doi.org/10.1007/s10549-013-2442-0

[30] Mor-Vaknin, N., Sitwala, K. and Markovitz, D.M. (2003) Vimentin Is Secreted by Activated Macrophages. Nature Cell Biology, 5, 59-63. http://dx.doi.org/10.1038/ncb898

[31] Kallergi, G., Politaki, E., Mavroudis, D., Georgoulias, V. and Agelaki, S. (2011) Epithelial to Mesenchymal Transition Markers Expressed in Circulating Tumor Cells of Early and Metastatic Breast Cancer Patients. Breast Cancer Research, 13, R59. http://dx.doi.org/10.1186/bcr2896

[32] Chaffer, C.L., Brennan, J.P., Slavin, J.L., Blick, T., Thompson, E.W. and Williams, E.D. (2006) Mesenchymal-to-Epithelial Transition Facilitates Bladder Cancer Metastasis: Role of Fibroblast Growth Factor Receptor-2. Cancer Research, 66, 11271-11278. http://dx.doi.org/10.1158/0008-5472.CAN-06-2044

[33] Gjerdrum, C., Tiron, C., Hoiby, T., Stefansson, I., Haugen, H., Sandal, T., Collett, K., Li, S., McCormack, E., Gjertsen, B.T., Micklem, D.R., Akslen, L.A., Glackin, C. and Lorens, J.B. (2010) Axl Is an Essential Epithelial-to-Mesenchymal Transition-Induced Regulator of Breast Cancer Metastasis and Patient Survival. Proceedings of the National Academy of Sciences of the United States of America, 107, 1124-1129. http://dx.doi.org/10.1073/pnas.0909333107

[34] Holland, S.J., Powell, M.J., Franci, C., Chan, E.W., Friera, A.M., Atchison, R.E., McLaughlin, J., Swift, S.E., Pali, E.S., Yam, G., Wong, S., Lasaga, J., Shen, M.R., Yu, S., Xu, W., Hitoshi, Y., Bogenberger, J., Nor, J.E., Payan, D.G. and Lorens, J.B. (2005) Multiple Roles for the Receptor Tyrosine Kinase Axl in Tumor Formation. Cancer Research, 65, 9294-9303. http://dx.doi.org/10.1158/0008-5472.CAN-05-0993

[35] Fuyuhiro, Y., Yashiro, M., Noda, S., Kashiwagi, S., Matsuoka, J., Doi, Y., et al. (2010) Clinical Significance of Vimentin-Positive Gastric Cancer Cells. Anticancer Research, 30, 52395243.

[36] Jin, H., Morohashi, S., Sato, F., Kudo, Y., Akasaka, H., Tsutsumi, S., et al. (2010) Vimentin Expression of Esophageal Squamous Cell Carcinoma and Its Aggressive Potential for Lymph Node Metastasis. BioMed Research, 31, 105-112. http://dx.doi.org/10.2220/biomedres.31.105

[37] Alfonso, P., Nunez, A., Madoz-Gurpide, J., Lombardia, L., Sanchez, L. and Casal, J.I. (2005) Proteomic Expression Analysis of Colorectal Cancer by Two-Dimensional Differential Gel Electrophoresis. Proteomics, 5, 2602-2611. http://dx.doi.org/10.1002/pmic.200401196 
[38] McInroy, L. and Maatta, A. (2007) Down-Regulation of Vimentin Expression Inhibits Carcinoma Cell Migration and Adhesion. Biochemical and Biophysical Research Communications, 360, 109-114. http://dx.doi.org/10.1016/j.bbrc.2007.06.036

[39] Hong, S.H., Misek, D.E., Wang, H., Puravs, E., Hinderer, R., Giordano, T.J., et al. (2006) Identification of a Specific Vimentin Isoform That Induces an Antibody Response in Pancreatic Cancer. Biomarker Insights, 1, 175-183.

[40] Walsh, N., O’Donovan, N., Kennedy, S., Henry, M., Meleady, P., Clynes, M., et al. (2009) Identification of Pancreatic Cancer Invasion-Related Proteins by Proteomic Analysis. Proteome Science, 7, 3. http://dx.doi.org/10.1186/1477-5956-7-3

[41] Korsching, E., Packeisen, J., Liedtke, C., Hungermann, D., Wulfing, P., van Diest, P.J., et al. (2005) The Origin of Vimentin Expression in Invasive Breast Cancer: Epithelial-Mesenchymal Transition, Myoepithelial Histogenesis or Histogenesis from Progenitor Cells with Bilinear Differentiation Potential. Journal of Pathology, 206, 451-457.

http://dx.doi.org/10.1002/path.1797

[42] Li, M., Zhang, B., Sun, B., Wang, X., Ban, X., Sun, T., et al. (2010) A Novel Function for Vimentin: The Potential Biomarker for Predicting Melanoma Hematogenous Metastasis. Journal of Experimental and Clinical Cancer Research, 29, 109. http://dx.doi.org/10.1186/1756-9966-29-109

[43] Fortin, S., Le Mercier, M., Camby, I., Spiegl-Kreinecker, S., Berger, W., Lefranc, F., et al. (2010) Galectin-1 Is Implicated in the Protein Kinase C Epsilon/Vimentin-Controlled Trafficking of Integrin-Beta1 in Glioblastoma Cells. Brain Pathology, 20, 39-49. http://dx.doi.org/10.1111/j.1750-3639.2008.00227.x

[44] Li, Z.M., Wen, Y.J., Yang, H.B., Qin, G., Tian, L., Deng, H.X., et al. (2008) Enhanced Expression of Human Vimentin Intermediate Filaments in Hepatocellular Carcinoma Cells Decreases Their Proliferative and Invasive Abilities in Vitro. Chinese Journal of Oncology, 30, 408-412.

[45] Bouamrani, A., Ramus, C., Gay, E., Pelletier, L., Cubizolles, M., Brugiere, S., et al. (2010) Increased Phosphorylation of Vimentin in Noninfiltrative Meningiomas. PLoS ONE, 5, e9238. http://dx.doi.org/10.1371/journal.pone.0009238

[46] Chen, W., Han, Z.J., Skoletsk, J., Olson, J., Sah, J., Myeroff, L., et al. (2005) Detection in Fecal DNA of Colon Cancer-Specific Methylation of the Nonexpressed Vimentin Gene. Journal of the National Cancer Institute, 97, 1124-1132.

http://dx.doi.org/10.1093/jnci/dji204 
Submit or recommend next manuscript to SCIRP and we will provide best service for you:

Accepting pre-submission inquiries through Email, Facebook, LinkedIn, Twitter, etc. A wide selection of journals (inclusive of 9 subjects, more than 200 journals)

Providing 24-hour high-quality service

User-friendly online submission system

Fair and swift peer-review system

Efficient typesetting and proofreading procedure

Display of the result of downloads and visits, as well as the number of cited articles

Maximum dissemination of your research work

Submit your manuscript at: http://papersubmission.scirp.org/

Or contact abcr@scirp.org 